
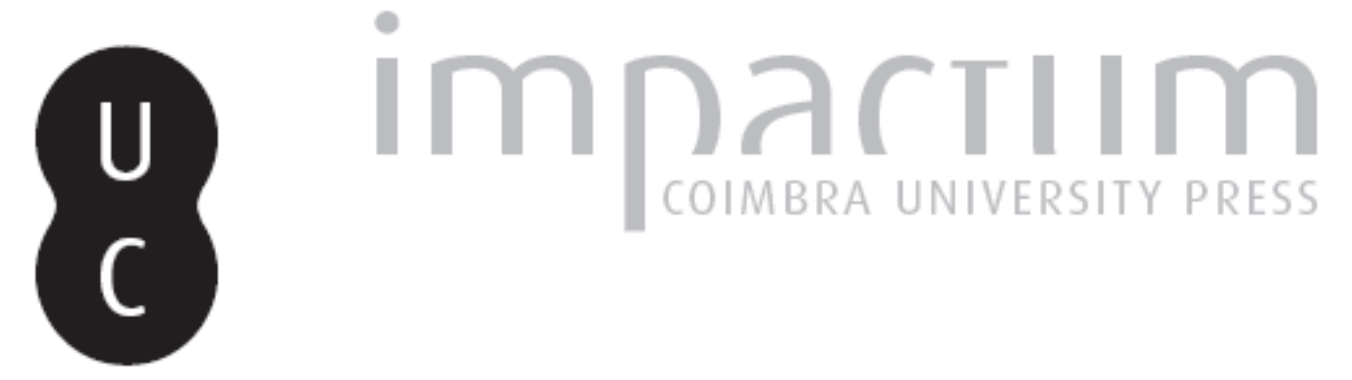

\title{
O sétimo centenário de Petrarca entre Portugal e a Itália
}

\author{
Autor(es): Marnoto, Rita
}

Publicado por: Imprensa da Universidade de Coimbra

URL persistente:

URl:http://hdl.handle.net/10316.2/42686

DOI:

DOl:https://doi.org/10.14195/0870-8584_1_5

Accessed : $\quad$ 26-Apr-2023 15:46:56

A navegação consulta e descarregamento dos títulos inseridos nas Bibliotecas Digitais UC Digitalis, UC Pombalina e UC Impactum, pressupõem a aceitação plena e sem reservas dos Termos e Condições de Uso destas Bibliotecas Digitais, disponíveis em https://digitalis.uc.pt/pt-pt/termos.

Conforme exposto nos referidos Termos e Condições de Uso, o descarregamento de títulos de acesso restrito requer uma licença válida de autorização devendo o utilizador aceder ao(s) documento(s) a partir de um endereço de IP da instituição detentora da supramencionada licença.

Ao utilizador é apenas permitido o descarregamento para uso pessoal, pelo que o emprego do(s) título(s) descarregado(s) para outro fim, designadamente comercial, carece de autorização do respetivo autor ou editor da obra.

Na medida em que todas as obras da UC Digitalis se encontram protegidas pelo Código do Direito de Autor e Direitos Conexos e demais legislação aplicável, toda a cópia, parcial ou total, deste documento, nos casos em que é legalmente admitida, deverá conter ou fazer-se acompanhar por este aviso.

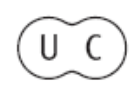




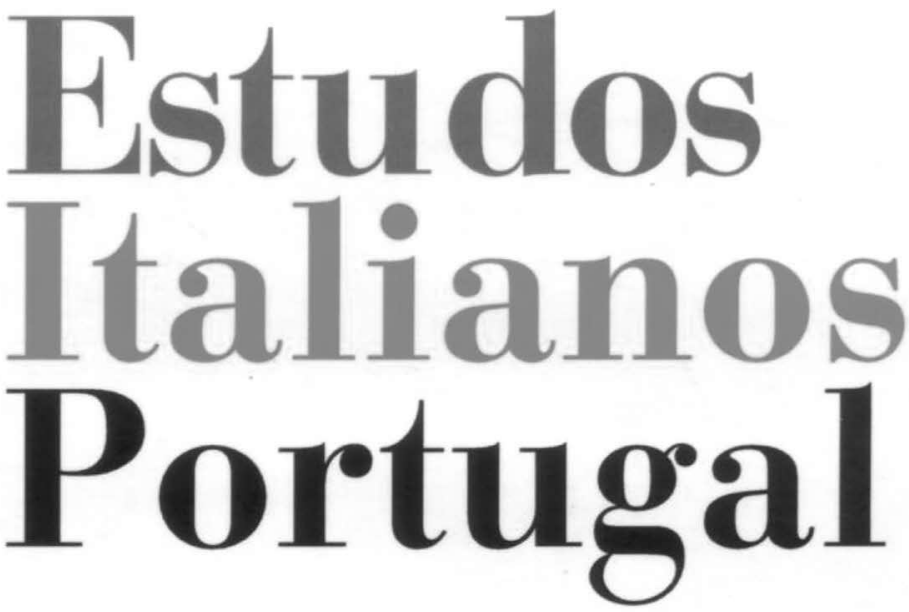

Instituto

Italiano

de Cultura

em Portugal

Nova Série

$\mathbf{N}^{\circ} \mathbf{1}$

2006 


\title{
O SÉTIMO CENTENÁRIO DE PETRARCA ENTRE PORTUGAL E A ITÁLIA
}

\author{
Rita Marnoto
}

Petrarca é um marco Miliário na história da cultura: "Não é, de modo algum, uma forma ritualizada, a que faz de Petrarca um autêntico mestre do saber europeu, pai daquele Humanismo que tem no cruzamento entre saberes, humanae litterae e empenhamento cívico de fundo ético, uma das suas mais originais particularidades", sublinha Gian Mario Anselmi ao iniciar a conferência que proferiu ao Congresso Internacional, Petrarca 700 anos. O petrarquismo português, organizado pelo Instituto Internacional da Casa de Mateus ${ }^{1}$. $\mathrm{Na}$ verdade, remonta ao seu magistério o impulso à refundação de uma Roma, de uma Itália e de um mundo à luz de uma perspectiva de grande alcance, pedra basilar daquele projecto inclusivo que hoje dizemos europeu.

Nascido em Arezzo, mantém, até meados do século, uma casa em Vaucluse, na Provença. Aí se retira para se dedicar à escrita. Contudo, as suas relações com a cúria de Avinhão e com a poderosa família dos Colonna são muito próximas. Visita o Norte da Europa e a Europa central. Mas a viagem que mais o impressiona é a que faz a Roma, em 1336. As ruínas do Império, que então se encontravam ao abandono,

${ }^{1}$ Petrarca 700 anos, coordenação de Rita Marnoto, Coimbra, Instituto de Estudos Italianos da Faculdade de Letras da Universidade de Coimbra, 2005 , p. 103. 
comovem-no profundamente. Quatro anos depois, lá há-de regressar para ser coroado com louros, como os poetas da Antiguidade. Tinha recusado o convite que lhe fora feito pela Universidade de Paris para receber essa distinção. É que a Universidade de Paris era o grande baluarte da escolástica, esse mesmo método que Petrarca combatia. A partir de 1352, e até à sua morte, em 1374, deambulará por várias cidades do Norte da Itália. Bocácio, mais novo do que ele cerca de dez anos, censura-o por aceitar a protecção dos Visconti, que eram considerados tiranos. Responde-lhe com uma carta onde lhe diz que a única liberdade é a do espírito e que o seu espírito é verdadeiramente livre. Como autor de culto, não tardou também a ter os seus lugares de culto. Vaucluse logo se tornou meta de peregrinação. Francisco de Holanda, quando regressa de Itália, em 1540, faz um desvio na rota dos Alpes para ir a Vaucluse. Fixou a sua imagem num desenho aguarelado que constitui a primeira representação paisagística do lugar.

A amigos, funcionários das chancelarias, ou, até, a pessoas que só muito vagamente conhecia, solicitava com insistência notícias de manuscritos da Antiguidade que eventualmente se encontrassem adormecidos pelas prateleiras das suas bibliotecas. Não se tratava, de modo algum, de fazer uma mera colagem de um passado sobre um presente. É fascinante, considerado à luz da teoria hermenêutica contemporânea, o sentido que Petrarca confere à temporalidade. Ler os clássicos, ler os autores medievais, tem sentido em função de uma actualização que se oferece ao futuro, através do projecto humanista. Os objectivos civilizacionais da Antiga Roma são transpostos para a cerimónia do Capitólio, onde é coroado por um Senador romano, mas só depois de ter sido examinado pelo rei Roberto de Nápoles, que considerava a figura mais culta do seu tempo. Os ideais políticos da urbs são traduzidos através do apoio que dá a Cola di Rienzo, o que lhe custa o distanciamento da família dos Colonna, seus protectores. Da mesma forma, e a cada momento, sujeita esse passado a uma eloquente análise crítica, particularmente severa para com a escolástica. A fórmula que faz dele o primeiro moderno tem um valor emblemático.

Em latim, escreveu tratados, cartas, um guia de viagem até à Terra Santa, comentários à margem dos livros que lia, e até as apostilhas às suas duas únicas obras em vulgar. Fez-nos crer que a sua língua era a dos autores áureos do Império romano. Escreveu duas obras em vulgar italiano, o Cancioneiro e os Triunfos, às quais, mesmo assim, deu títulos latinos, Triumphi e Rerum vulgarium fragmenta. Os Triumphi não foram acabados. Por sua vez, trabalhou no livro dos Fragmenta até ao fim dos seus dias e deixou ainda páginas em branco intercaladas para copiar mais poemas. Quando lhes chama nugae, deixa-nos perplexos. Sinceridade pura? Gosto de erudito, ao repetir o mesmo que Catulo dizia dos seus versos? Atitude de um humanista dividido entre o dever programático de usar só o latim, e as emoções da língua que criou? O certo é que, para o senso comum, Petrarca ficou célebre como amante de Laura. A sua poesia tem tamanha excelência e foi-lhe concedida uma tal autoridade literária que ficou consagrada por uma tradição que se estende até aos nossos dias.

O Cancioneiro, por antonomásia, foi o pilar sobre o qual se firmou a lírica moderna. Resulta de uma intersecção, extremamente refinada, entre a poesia da Antiguidade, dolce stil novo e herança trovadoresca. O cruzamento de componentes tão vários só é possível em função de uma plataforma comum muito forte: a intimidade com que o amante ousa desdobrar todos os acordes de uma alma que vive dividida entre o anseio de alcançar a felicidade à face da Terra, amando Laura como mulher, e a consciência pecaminosa de quem sabe que Laura é um anjo, e como tal só pode ser adorada à distância. Por essa via, Petrarca rasga aquele des- 
centramento que é condição do ser que se pensa. Foi um criador de ficções. Se lhe chamam o primeiro moderno, é também porque criou interrogando, descentrando, tirando partido da ambiguidade. Colocou aos seus leitores dúvidas que ainda hoje continuam a suscitar vivas controvérsias, e hão-de continuar a suscitá-las. Reinventou o seu nome quando foi aluno da Universidade de Montpellier. Não tinha nome de família. O seu pai chamava-se Petracco, diminutivo de Petro, e, a partir daí, construiu o nome de Petrarca, mais soante. Dedicou o seu amor a uma criatura cuja existência deixou envolta num halo de ambiguidades. Giovanni Colonna ter-lhe-ia escrito uma carta a dizer que esse amor era fingimento. Responde-lhe de forma enfática, queixando-se de quanto sofre por Laura. Mas a tal carta de Giovanni Colonna nunca foi encontrada. Expediente para criar um efeito de realidade? No seu mais querido manuscrito, Virgílio, anota a morte de Laura, na peste de 1348. Mas continua a dedicar-lhe versos como se estivesse viva. A personagem de Augustinus, no diálogo Secretum, diz que Laura era uma mulher casada que teve muitos filhos. Adverte Franciscus por amar o nome de uma mulher, um nome cujo som é semelhante ao da palavra que designa o louro com que são coroados os poetas laureados. Nos seus versos, tudo volteia em torno de um centro, o "eu" do poeta. O célebre sentimento da natureza, o mais raramente referido sentimento do tempo, a figura feminina, tudo isso ganha forma literária em função da sua subjectividade. Laura é o centro aparente da poesia, o objecto da palavra, do desejo da palavra. O verdadeiro centro é o poeta. Por esta via, Petrarca consagra o lirismo como espaço de descentramento. Do poeta, faz um eterno peregrino por entre as fendas da linguagem. Da figura feminina, faz centro aparente e descentrado. Falar de alguém que é objecto de desejo e objecto de palavra, peregrinando pelo eterno vazio da linguagem. No limiar do Moderno, para lá do Moderno, é a essência do lirismo.
É dessa nesga de inquietude que brotam os fundamentos de um código poético de incidência secular que serviu de "auto-estrada" a todo o lirismo, para usar uma feliz expressão de Amedeo Quondam, até ao advento do Romantismo². $\mathrm{Na}$ literatura portuguesa, a imitação de Petrarca ficou traduzida através de um fenómeno extraordinariamente rico, o petrarquismo português. A distância, no espaço e no tempo, que corria entre a ponta ocidental da Europa, e esse centro irradiador de modelos dotados de uma enorme capacidade propulsora, que era a Itália, favoreceu fenómenos de hibridismo que só muito parcelarmente encontraram correspondente noutras literaturas europeias. A vitalidade do petrarquismo português decorre, em boa parte, da facilidade com que o antigo e o novo entram em diálogo franco, num panorama aberto mas, ao mesmo tempo, caracterizado por permanências de substrato muito activas. Essa articulação encontrou em Camões, sem dúvida, o seu genial intérprete, pelo modo como soube representar o dissídio entre a Terra e o Céu, entre o bicho tão pequeno e a desmesura dos seus anseios. Mas está bem patente na actualidade, quer no plano da criação literária, quer em âmbito crítico, e sem se restringir à cultura erudita. Laura: foi o nome escolhido para a revista de arquitectura da Universidade do Minho.

A vastidão dos territórios postos em movimento pela figura de Francesco Petrarca e pela tradição que do seu magistério irradia erigiu-se, pois, com as celebrações do sétimo centenário do seu nascimento, em motivo particularmente propício para a dinamização do intercâmbio cultural luso-italiano.

Recorde-se, antes de mais, que para preparar as comemorações o Governo italiano criou uma Comissão Nacional, presidida por Michele Feo. Na página <http://www.franciscus. unifi.it/>, encontram-se disponíveis muitas informações

2 Il naso di Laura. Lingua e poesia lirica nella tradizione del Classicismo, Ferrara, Modena, Istituto di Studi Rinascimentali, Panini, 1991. 
acerca de eventos, projectos e publicações associados à efeméride. O ponto da situação, com respeito à edição nacional da obra do poeta e a outros projectos de investigação em curso, fica contido no nutrido catálogo da exposição que em finais de 2003 foi inaugurada em Arezzo, para depois ser vista em outras cidades italianas ${ }^{3}$. Actualmente, está em curso a realização de um dicionário temático e de uma outra exposição, desta feita dedicada à biblioteca de Petrarca. Subjaz-lhe, também neste caso, um trabalho de investigação cujas conclusões irão ser sintetizadas, da mesma forma, no catálogo da mostra. Sob a égide dessa comissão, foram publicados alguns textos do Petrarca latino ${ }^{4}$.

Pelo que diz respeito ao Petrarca em vulgar, tem o público-leitor à sua disposição guias indispensáveis para uma abordagem em profundidade dos Rerum vulgarium fragmenta e dos Triumphi. Em 1996, na colecção I Meridiani, foram editados dois portentosos comentários, um ao Cancioneiro, feito por Marco Santagata, outro aos Triumphi, com as rimas extravagantes e o codice degli abbozzi, por Vinicio Pacca e Laura Paolino ${ }^{5}$. Do comentário à primeira dessas obras, foi feita uma

3 Petrarca nel Tempo. Tradizione, lettori e immagini delle opere, a cura di Michele Feo, Comitato Nazionale per il VII Centenario della Nascita di F. Petrarca, 2003.

${ }^{4}$ Foram editados pela Comissão do Centenário ou com o seu apoio: F. Petrarca, Senile V 2, a cura di M. Berté, Firenze, Le Lettere, 1998; E. Rauner, Petrarca-Handschriften in Tscechien und in der slowakischen Republik, Padova, Antenore, 1999; Federica Santirosi, Le postille del Petrarca ad Ambrogio (codice parigino Lat. 1757), Firenze, Le Lettere, 2004; Laura Refe, Le postille del Petrarca a Giuseppe Flavio (codice parigino Lat. 5054), Firenze, Le Lettere, 2004; Francesco Petrarca, Contra eum qui maledixit Italie, a cura di Monica Berté, Firenze, Le Lettere, 2005; Francesco Petrarca, Invective contra medicum. Invectiva contra quendam magni status hominem sed nullius scientie aut virtutis, a cura di Francesco Bausi, Firenze, Le Lettere, 2005.

${ }^{5}$ Francesco Petrarca, Trionfi, rime estravaganti, codice degli abbozzi, a cura di Vinicio Pacca e Laura Paolino, introduzione di Marco Santagata, Milano, Mondadori, 1996, com sucessivas reimpressões. nova edição actualizada em $2004^{6}$. Entretanto, a um panorama já por si tão rico, veio-se a acrescentar, mais recentemente, o monumental comentário ao Cancioneiro que Rosanna Bettarini há longos anos tinha em preparação ${ }^{7}$.

No quadro do intercâmbio luso-italiano, e continuando a fixar a nossa atenção sobre o que se tem vindo a fazer em Itália, não escassearam focos de dinamização. A presença de Petrarca em Portugal foi objecto de ensaios especializados, de intervenções em congressos ${ }^{8}$ e de apresentações panorâmicas. Os estudiosos do petrarquismo foram presenteados com a notícia da posse, por parte da Fundação Calouste Gulbenkian, de um importante manuscrito com o Cancioneiro e os Triumphi, decorado com delicadas iluminuras, que foi executado pela bottega florentina de Francesco d'Antonio del Chierico. Adquirido pelo próprio Gulbenkian, sofreu depois danos que implicaram um aturado e delicado trabalho de restauro, pelo que permaneceu inacessível durante um certo período de tempo. O seu estudo específico foi levado a cabo por Aires A. Nascimento, num ensaio que

\footnotetext{
${ }^{6}$ Francesco Petrarca, Canzoniere, edizione commentata a cura di Marco Santagata, nuova edizione aggiornata, Milano, Mondadori, 2004. A mesma editora projecta lançá-lo, brevemente, numa modalidade económica de grande tiragem. Foi também editado, no presente ano de 2006, em tradução polaca.

7 Canzoniere. Rerum vulgarium fragmenta, a cura di Rosanna Bettarini, Torino, Einaudi, 2005, 2 v.

8 A saber, "Petrarca in Portogallo. 'Ad eorum littus irem', , conferência apresentada ao Convegno Internazionale di Studi Petrarca nel Mondo, realizado em Incisa in Val d'Arno em Julho de 2004; e "Laura bianca, Bárbora nera. Le letture di Camões come riconversione al canone", conferência apresentada ao congresso realizado na Universidade de Bolonha, Il Petrarchismo: un Modello di Poesia per l'Europa. Convegno Internazionale di Studi, em Outubro do mesmo ano. As actas desses congressos encontram-se em preparação. Recorde-se também "Riscoprire Petrarca. Petrarca, Camões, Manuel Alegre, Alexandre O’Neill”, conferência realizada no Departamento de Línguas e Culturas Neolatinas da Universidade de Florença. Proferidas por Rita Marnoto.
} 
publicou em Itália, na revista Cultura Neolatina9 ${ }^{9}$ Essas páginas erigem-se em oportunidade, além do mais, para a revisão de questões que se prendem com a presença de manuscritos de Petrarca nas bibliotecas portuguesas. Por sua vez, num artigo editado na revista Critica del Testo, Rita Marnoto desenha o percurso do petrarquismo português quinhentista, acompanhando o modo como é elaborada a translação recriativa do soneto de abertura do Cancioneiro ${ }^{10}$. No quadro das visões de conjunto do fenómeno do petrarquismo, a especificidade da situação portuguesa é contemplada pela antologia Lirici europei del Cinquecento. Ripensando la poesia del Petrarca, organizada por Gian Mario Anselmi, Keir Elam, Giorgio Forni e Davide Monda, bem como pelos números temáticos com que as revistas In Forma di Parole e L'Erasmo recordaram a efeméride. $\mathrm{Na}$ antologia de Anselmi, a nota de apresentação do petrarquismo português, assinada por Roberto Mulinacci, é acompanhada por uma antologia poética bilingue ${ }^{11}$. Também a introdução crítica de Valeria Tocco publicada em In Forma di Parole tem por sequência um florilégio bilingue ${ }^{12}$. Por sua vez, em L'Erasmo, Rita Marnoto faz uma interpretação do petrarquismo português, focando as suas relocações a Leste e a Oeste ${ }^{13}$.

Se, de Itália, passarmos para Portugal e para as actividades promovidas no mesmo âmbito, destacam-se dois congressos,

9 "Manuscrito quatrocentista de Petrarca na Colecção Calouste Gulbenkian, em Lisboa: Canzoniere e Triumphi”: Cultura Neolatina, 64, 3-4, 2004, pp. 325-410.

10 "Spero trovar pietà, nonché perdono. Tradução e imitação no lirismo português do século XVI": Critica del Testo, 6, 2, 2003, pp. 837-851.

11 "Un'immagine del petrarchismo portoghese", de Roberto Mulinacci, pp. 1073-1129 da citada antologia, Milano, Rizzoli, 2004.

12 "Petrarca in Portogallo", a cura di Valeria Tocco: In Forma di Parole, 2, 1 [Petrarca in Europa], 4a s., 24, 4, 1, 2004, pp. 110-196.

${ }^{13}$ Rita Marnoto, "Dove Petrarca scrisi. Loco beato. Petrarchismo transculturale: il Portogallo del Cinquecento nelle rotte oceaniche”: L'Erasmo, 22, 2004, pp. 54-60. o Segundo Encontro de Italianística. Petrarca 700 Anos. Instituto de Estudos Italianos 75 anos, organizado a 4 e 5 de Maio de 2004 pelo Instituto de Estudos Italianos da Faculdade de Letras da Universidade de Coimbra, e o Congresso Internacional, Petrarca 700 anos. O Petrarquismo Português, organizado pelo Instituto Internacional da Casa de Mateus de 11 a 13 de Junho em Mateus, e cujas conclusões foram apresentadas à Universidade de Coimbra a 14 de Junho. As actas dos dois simpósios foram publicadas conjuntamente num volume que se reparte por quatro secções ${ }^{14}$ : Petrarca na actualidade (Luciana Stegagno Picchio, João R. Figueiredo, Xosé Manuel Dasilva, Vasco Graça Moura, Fernando J. B. Martinho e Giulio Ferroni); A afirmação do cânone na Itália do "Cinquecento" (Gian Mario Anselmi, Roberto Gigliucci, Manuel Cadafaz de Matos e Amedeo Quondam); Percursos do petrarquismo na Península Ibérica (Rita Marnoto, Maria Manuela Toscano, Sylvie Deswarte-Rosa, Soledad Pérez-Abadín Barro, Maria Manuel Baptista, Hélio J. Alves e Giulia Poggi); e O tempo de Petrarca (Leonel Ribeiro dos Santos e Giona Tuccini). Por sua vez, na Faculdade de Letras da Universidade de Lisboa, Ernesto Rodrigues e Isabel Almeida integraram no ciclo Do Renascimento ao Barroco a conferência "Petrarca, entre Portugal, a Itália e as rotas oceânicas", proferida por Rita Marnoto a 22 de Março de 2004.

Quanto à actividade editorial levada a cabo por revistas portuguesas especializadas, dedicaram números monográficos a Petrarca e ao petrarquismo a Revista Portuguesa de História do Livro, com um conjunto de estudos, repartido por dois números, que homenageia Eugenio Garin ${ }^{15}$, e Euphrosyne. Revista de Filologia Clássica $^{16}$. Na primeira colaboram José V. de Pina

14 Petrarca 700 anos, coordenação de Rita Marnoto, Coimbra, Instituto de Estudos Italianos da Faculdade de Letras da Universidade de Coimbra, 2005. 15 Ano 8, n. 15 e 16 de 2004.

16 N. s., 33, 2005 
Martins, Rita Marnoto, Jean Lacroix, Enric Tormo Ballester, Manuel Cadafaz de Matos, Vanda Anastácio, Francesco Soave, Luís André Nepomuceno e Maria Valentina Mendes. A segunda publica uma série de estudos que privilegia a vertente latina, de Alain Michel, Francesco Tateo, Silvia Rizzo, Rodney Lokaj, Alejandro Coroleu, Fabio Stok, Guillermo Serés, Maria Elisa Lage Cotos, Ida Mastrorosa, Carlo Santini, Jan den Boeft e Ana María Sánchez Tarrío. Na secção de recensões, é incluída uma nota, redigida por Aires A. Nascimento, sobre as edições da obra de Francesco Petrarca que têm vindo a ser dadas ao prelo em França ${ }^{17}$. Também em Portugal se esperam avanços no sentido da disponibilização da sua obra latina em tradução portuguesa. O texto das epístolas Familiares está a ser traduzido para Imprensa Nacional-Casa da Moeda.

Pelo que diz respeito ao Petrarca em vulgar, o centenário do nascimento coincidiu com a edição da primeira tradução completa $^{18}$, publicada em Portugal, do Cancioneiro e dos Triumphi, elaborada por Vasco Graça Moura. Em ambos os volumes, original italiano e versão portuguesa são colocados face a face, precedidos por uma introdução e acompanhados por algumas notas explicativas. O Cancioneiro foi galardoado com o prémio internacional Diego Valeri 2004, no âmbito do prémio Monselice para a tradução. A atribuição à mesma obra, pela Universidade de Coimbra, no presente ano de 2006, do prémio de tradução para poesia Paulo Quintela, mostra como os caminhos que passam por Petrarca e pela difusão e recriação do seu magistério, entre Portugal e a Itália, correm por vias convergentes.

17 Pp. 484-486.

18 Acerca da identidade do primeiro tradutor do Cancioneiro para castelhano, o judeu de origem portuguesa Salomão Usque, escreveu António Andrade, "A figura de Salomão Usque: a face oculta do humanismo judaico-português": Gramática e Humanismo. Actas do Colóquio de homenagem a Amadeu Torres, Miguel Gonçalves et alii (org.), Braga, Faculdade de Filosofia, Universidade Católica Portuguesa, 2005, vol. 2, pp. 15-25. 